\title{
Chemical Vapour Deposition of Reactive Organogermanium Films by Laser-induced Decomposition of Tetramethoxygermane
}

\author{
Josef Pola, ${ }^{\star a}$ Radek Fajgar, ${ }^{a}$ Zdenĕk Bastl ${ }^{b}$ and Luis Diaz ${ }^{\star c}$ \\ a Institute of Chemical Process Fundamentals, CSAV, 16502 Prague, Czechoslovakia \\ ${ }^{b} \mathrm{~J}$. Heyrovsky Institute of Physical Chemistry and Electrochemistry, CSAV, 18223 Prague, \\ Czechoslovakia \\ Institute of Optics, CSIC, 28006 Madrid, Spain
}

\begin{abstract}
Laser-induced multiphoton and $\mathrm{SF}_{6}$-photosensitised decomposition of tetramethoxygermane has been used for chemical vapour deposition of reactive organooxogermanium polymers, which were characterised by IR, VIS, and UV spectra and ESCA and TEM techniques. The properties of the deposited layers differed depending on the mode of tetramethoxygermane decomposition. The films were reactive towards the ambient atmosphere; this is discussed in terms of the reaction of $\mathrm{CH}_{3} \mathrm{OGe}$ groups with air moisture.
\end{abstract}

Keywords: Chemical vapour deposition; Laser-induced decomposition; Thin film; Tetramethoxygermane

Considerable interest has been attached to the possibility of producing polymeric organogermanium oxides, analogous to silicones, using hydrolysis of dihalo ${ }^{1-3}$ and dialkoxygermanes. ${ }^{4-6}$ It was soon recognised, however, that the hydrolytic preparation of these organooxogermanium polymers cannot be achieved efficiently, ${ }^{1,2}$ owing to formation of lowmolecular-weight, water-soluble oligomers. Polymeric organogermanium oxides cannot be obtained by hydrolysis of either organylgermanium trichlorides or tetraalkoxygermanes. The former are known to yield cage-like molecules, ${ }^{6-9}$ whereas the latter afford germanium dioxide ${ }^{10}$ or a mixture of some polymeric substances along with $\left[(\mathrm{RO})_{3} \mathrm{Ge}\right]_{2} \mathrm{O} .^{5}$

An alternative technique for the production of polymeric organooxogermanes is the radical decomposition of alkylalkoxygermanes in the gas phase. Metallo-organic chemical vapour deposition (MOCVD), using an organogermanium precursor, has been only briefly investigated so far. The sole examples are pyrolytic ${ }^{11}$ and plasma-induced ${ }^{12}$ decomposition of tetraethyoxygermane, affording germanium dioxide.

Encouraged by our previous studies on the chemical vapour deposition of some organosilicon polymers by laser-induced decomposition of tetramethoxysilane ${ }^{13}$ and multiphoton decomposition of silane in the presence of some monomers, ${ }^{14-16}$ we report in this paper the gas-phase laser-induced decomposition of tetramethoxygermane (TMG) and address the problem of the use of direct infrared multiphoton decomposition and $\mathrm{SF}_{6}$-photosensitised homogeneous thermolysis as a technique for the preparation (deposition) of polymeric layers containing $\mathrm{C}, \mathrm{H}, \mathrm{O}$, and $\mathrm{Ge}$.

\section{Experimental}

The experiments were performed in a cylindrical $10 \mathrm{~cm}$ glass tube (inner diameter, $3.6 \mathrm{~cm}$ ), with $\mathrm{KBr}$ windows and a PTFE stopcock. A thin plate $\left(\mathrm{ca} .4 \mathrm{~cm}^{2}\right)$ of substrate was positioned close to the entrance window. Liquid TMG was kept in a side-arm separated from the tube by another PTFE tap. It was repeatedly frozen and thawed under vacuum to remove traces of more volatile methanol present as trace impurity, and then introduced into the tube at a pressure up to $700 \mathrm{~Pa}$. Sulfur hexafluoride, when used, was expanded into the cell from a standard vacuum line.

A grating-tuned TEA $\mathrm{CO}_{2}$ laser ${ }^{17}$ was operated on the $P(26)$ line of the $00^{\circ} 1 \rightarrow 10^{\circ} 0$ transition to achieve absorption in TMG. The $\mathrm{P}(20)$ line of the $00^{\circ} 1 \rightarrow 02^{\circ} 0$ transition was chosen for the irradiation of $\mathrm{TMG}-\mathrm{SF}_{6}$ mixtures when absorption in $\mathrm{SF}_{6}$ was effective. The laser-beam energy was measured with a laser energy pyroceramic sensor (Charles University, ml-1 JU model) and the wavelengths were checked with a model 16-A spectrum analyser (Optical Eng. Co.). The laser was fired at a repetition frequency of $5 \mathrm{~Hz}$.

The IR spectra before and after irradiation were recorded with a Specord 75 model (Zeiss) IR spectrometer. The depletion of TMG was monitored at $670 \mathrm{~cm}^{-1}$. Gaseous products of the laser-induced decomposition of TMG were identified by their absorption spectra (methane, $1300 \mathrm{~cm}^{-1}$; carbon monoxide, $2140 \mathrm{~cm}^{-1}$; methanol, 1030 and $3660 \mathrm{~cm}^{-1}$ ) and by their mass fragmentations and retention times. For the latter purpose, helium was expanded into the cell to atmospheric pressure and gaseous samples were injected into a GC/MS (Shimadzu QP 1000) quadrupole mass spectrometer (columns packed with alumina coated with silicon oil or silicon elastomer SE-300).

The deposit on glass or $\mathrm{NaCl}$ substrates was investigated by means of ESCA, scanning electron microscopy, TEM, VIS, UV, and IR spectroscopy. Transmission electron micrographs were made with a JEOL JEM $100 \mathrm{U}$ electron microscope operating at $100 \mathrm{kV}$.

ESCA measurements were made using a VG ESCA $3 \mathrm{Mk}$ II spectrometer with a base pressure of $<10^{-8} \mathrm{~Pa}$. Al-K $\alpha$ radiation $(1486.6 \mathrm{eV})$ was used for spectra excitation. The spectrometer was operated in the fixed-analyser transmission mode with a pass energy of $20 \mathrm{eV}$. Spectra were collected using a Commodore PC 10-111 computer and transferred to an HP PC/AT for data analysis. Spectra of Ge 3d, Ge 2p, $\mathrm{O}$ 1s levels were recorded. In addition, the kinetic energy of Ge $\mathrm{L}_{3} \mathbf{M}_{45} \mathbf{M}_{45}$ Auger electrons was measured. Binding energies were measured using the $\mathrm{C} 1 \mathrm{~s}$ peak $\left(E_{\mathrm{B}}=285.0 \mathrm{eV}\right)$ as internal standard. Peak area computation was performed after the non-linear background ${ }^{18}$ was removed. The atomic ratios were calculated taking into account the Scofield ${ }^{19}$ subshell photoionisation cross-sections. The estimated accuracy of the determined concentration amounts was $\pm 10 \%$.

VIS and UV transmission spectra of the deposit were measured, using a Perkin-Elmer Lambda 9 spectrometer, in the spectral range $190-2500 \mathrm{~nm}$.

TMG was prepared as reported ${ }^{20}$ and distilled under vacuum prior to use. Sulfur hexafluoride was purchased from Fluka. 


\section{Results and Discussion Infrared Multiphoton Decomposition (IRMPD)}

The infrared absorption spectrum of TMG in the gas phase shows bands at $680,1054,2840$, and $2940 \mathrm{~cm}^{-1}$ attributable to the $\mathrm{Ge}-\mathrm{O}$ and $\mathrm{C}-\mathrm{H}$ stretching vibrations. (We note the absence of additional absorption bands at 897 and $1460 \mathrm{~cm}^{-1}$ observed ${ }^{21}$ in the liquid sample.) Irradiation by the $\mathrm{CO}_{2}$ laser [the $\mathrm{P}(26)$ line of the $00^{\circ} 1 \rightarrow 02^{0} 0$ transition, $1041.3 \mathrm{~cm}^{-1}$, beam area $c a .1 .2 \mathrm{~cm}^{2}, 0.45 \mathrm{~J}$ in a pulse] at the IR transition of the $v(\mathrm{Ge}-\mathrm{O})$ mode of TMG $\left(1054 \mathrm{~cm}^{-1}\right.$, molar absorptivity $0.10 \mathrm{kPa}^{-1} \mathrm{~cm}^{-1}$ ) results in the formation of gaseous methanol, dimethoxymethane, and a compound with the composition $\mathrm{C}_{5} \mathrm{H}_{12} \mathrm{O}_{2}$. A solid brown layer, deposited on the entrance window and on a nearby surface of the reactor, is produced concomitantly. In these experiments, the laser beam was directed parallel to the substrate surface, the distance between the lower margin of the beam and the substrate being ca. $2 \mathrm{~mm}$. The TMG decomposition is enhanced with the increase in TMG pressure (Fig. 1), and this indicates that infrared multiphoton decomposition of TMG proceeds by a collisional mechanism. Upon irradiation of $0.6 \mathrm{kPa}$ of TMG with an incident energy of $0.45 \mathrm{~J}$ as much as $0.30 \mathrm{~J}$ is absorbed by $\mathrm{ca} .12 \mathrm{~cm}^{3}$ of the sample, which corresponds to an average of $E_{\mathrm{abs}} \approx 103 \mathrm{~kJ} \mathrm{~mol}^{-1}$, and hence, to an absorption of 8-9 photons per molecule and pulse. A typical temporal profile of the pulse ${ }^{17}$ consisted of a 150 ns (FWHM) peak, followed by a tail of $c a .1 \mu$ s duration, and it may be deduced that a TMG molecule can experience about eight collisions during the excitation time. An energy-pooling collision of two intermediate energised molecules, which yields molecules with sufficient energy to cleave the $\mathrm{Ge}-\mathrm{O}\left(300 \mathrm{~kJ} \mathrm{~mol}^{-1}\right.$, ref. 22) or $\mathrm{C}-\mathrm{O}$ (ca. $340 \mathrm{~kJ} \mathrm{~mol}^{-1}$, ref. 23) bond, can thus be invoked as an excitation mechanism.

We assume that the IRMPD of TMG involves cleavage of the weaker $\mathrm{Ge}-\mathrm{O}$ bond, the abstraction of hydrogen by the methoxy radical, and a cleavage of the trimethoxygermoxymethyl radical into the $\mathrm{CH}_{2} \mathrm{O}$ and $\left(\mathrm{CH}_{3} \mathrm{O}\right)_{3} \mathrm{Ge}$ radical:

$$
\begin{aligned}
& \left(\mathrm{CH}_{3} \mathrm{O}\right)_{3} \mathrm{GeOCH}_{3} \rightarrow \\
& \quad\left(\mathrm{CH}_{3} \stackrel{-}{\mathrm{O}}\right)_{3} \mathrm{Ge}^{\cdot}+\mathrm{CH}_{3} \mathrm{O} \cdot \frac{\mathrm{CH}_{2} \mathrm{O}}{-\frac{[\mathrm{H}]}{-\mathrm{CH}_{3} \mathrm{OH}}}\left(\mathrm{CH}_{3} \mathrm{O}\right)_{3} \mathrm{GeOCH}_{2}
\end{aligned}
$$

The occurrence of methanol and the reported reactions ${ }^{24}$ between this compound and formaldehyde, giving the observed dimethoxymethane, supports the above scheme. The trimethoxygermyl radical formed in this way can successively lose methoxy groups and also undergo recombination reactions. The enhancement of IRMPD with an increase of the initial pressure (Fig. 1) is in line with the fact that the decomposition cannot be completed once the TMG pressure

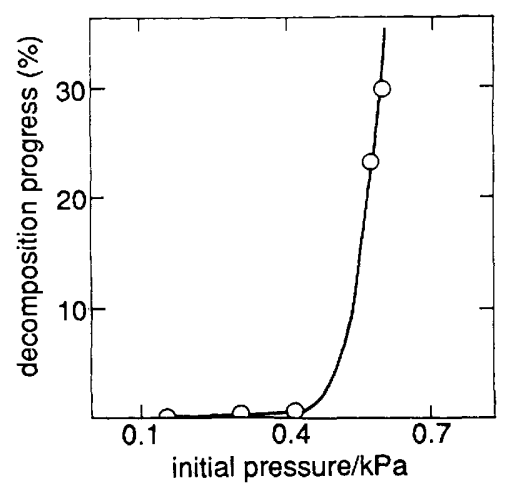

Fig. 1 Plot of TMG decomposition progress (after $10^{3}$ pulses) $v$. initial pressure is decreased below a pressure threshold. Indeed, the TMG decomposition can, regardless of the number of pulses, make only limited progress (Fig. 2). It is conceivable that this is caused not only by the depletion of TMG, but also by the increasing importance of deactivation collisions of TMG with the volatile reaction products.

\section{Photosensitised Decomposition (PSD)}

Irradiation of $\mathrm{TMG}^{-\mathrm{SF}_{6}}$ (both $0.5 \mathrm{kPa}$ ) mixtures by an unfocussed laser beam [the $\mathrm{P}(20)$ line of the $00^{\circ} 1 \rightarrow 10^{\circ} 0$ transition, $944.2 \mathrm{~cm}^{-1}$, beam area $c a .1 .2 \mathrm{~cm}^{2}$, energy in pulse 0.4-1.2 J] tuned to the $v_{3}$ mode of $\mathrm{SF}_{6}\left(965 \mathrm{~cm}^{-1}\right.$, molar absorptivity $0.98 \mathrm{kPa}^{-1} \mathrm{~cm}^{-1}$ ) can be considered ${ }^{25-27}$ to induce homogeneous thermolysis of TMG, which occurs in a limited volume of the gaseous sample. Sulfur hexafluoride takes part in this decomposition as an energy-conveying reagent and no decomposition products were detected. The laser beam entered the centre of the entrance window of the horizontally positioned cell and the energy $(0.40-1.2 \mathrm{~J})$ delivered to the system during a single pulse was completely absorbed. The irradiation resulted in a complete decomposition of TMG (Fig. 2), in the formation of volatile methane, carbon monoxide, methanol, and dimethoxymethane and in the deposition of a brown material on the window and walls of the cell.

It is clear that reactions taking place in the hot zone are more complicated than those occurring during IRMPD. Compounds that were not formed in the latter case were methane and carbon monoxide. We can assume that, owing to the higher temperatures in the hot zone, $\mathrm{CO}$ arises from the intermediate $\mathrm{CH}_{2} \mathrm{O}^{28}$ and that $\mathrm{CH}_{4}$ is produced via a cleavage of a stronger $\mathrm{O}-\mathrm{CH}_{3}$ bond and an abstraction of hydrogen by the $\mathrm{CH}_{3}$ radical from the parent TMG.

\section{Deposit Properties}

Different chemical processes occurring in the gas phase during IRMPD and the photosensitised decomposition of TMG are reflected in the differing compositions of deposited materials.

Infrared spectra of the deposits (Fig. 3) obtained by the two different decomposition processes of TMG show a similar pattern of strong absorption bands at $c a .650,850$, and $1000 \mathrm{~cm}^{-1}$. The first two can be attributed to $\mathrm{Ge}-\mathrm{O}$ vibrations, while the latter belongs to $v(\mathrm{C}-\mathrm{O})$ stretches. Broad bands of germanium-oxygen stretching vibrations are known ${ }^{29.30}$ to be sensitive to structural changes in the proxim-

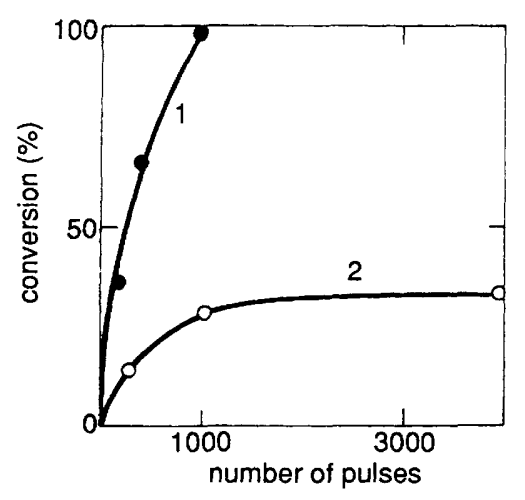

Fig. 2 Reaction progress of TMG decomposition in PSD experiments (curve 1 , both TMG and $\mathrm{SF}_{6}, 0.5 \mathrm{kPa}$ ) and in IRMPD experiments (curve $2,0.7 \mathrm{kPa}$ ) 


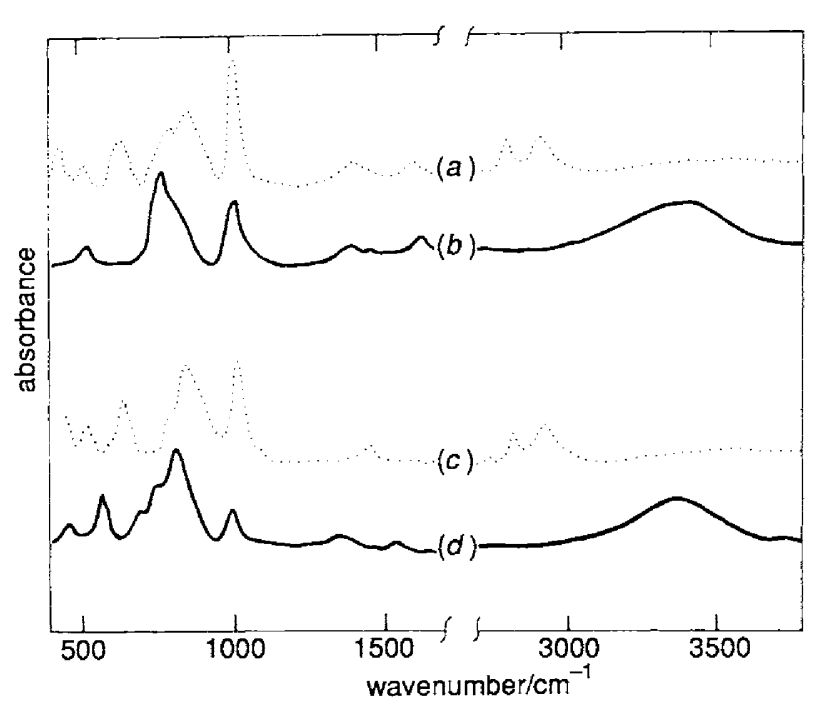

Fig. 3 Infrared spectra of the deposits produced upon IRMPD [(a), $(b)]$ and PSD $[(c),(d)]$ of $\left(\mathrm{CH}_{3} \mathrm{O}\right)_{4} \mathrm{Ge}$. Dotted lines relate to deposits after pumping off gaseous products; full curves correspond to deposits produced after evacuation, contact with the atmosphere and further evacuation

ity of the $\mathrm{GeO}$ bond and also to the degree of polymerisation. Different positions (and also patterns) of these absorption bands $\left(780 \mathrm{~cm}^{-1}\right.$, IRMPD; $805 \mathrm{~cm}^{-1}$, photosensitised experiments) thus indicate that the composition of the films obtained by the IRMPD and PSD processes varies. Minor dissimilarities in the IR spectra are also observed in the region of 1300 $1700 \mathrm{~cm}^{-1}$.

ESCA analysis of the deposits afforded by IRMPD and PSD of TMG reveals that the materials have different properties. The deposit resulting from IRMPD has composition $\mathrm{Ge}_{1.0} \mathrm{C}_{1.1} \mathrm{O}_{1.9}$. The stoichiometry did not depend on the photoelectron line of $\mathrm{Ge}$ used for calculation. We note that the sampling depth of the ESCA technique is proportional to $\lambda \sin \theta$, where $\lambda$ is the photoelectron escape depth in the sample under study and $\theta$ is the polar detection angle. For $\mathrm{Ge} 3 \mathrm{~d}$ electrons, the value of $\lambda$ is roughly 2.3 times higher than for $\mathrm{Ge} 2 \mathrm{p}$ electrons. The fact that the composition was independent of the photoelectron line used demonstrates that the sample was homogeneous within $c a .10 \mathrm{~nm}$.

The stoichiometry of the deposit prepared by PSD of the $\mathrm{TMG}-\mathrm{SF}_{6}$ mixture was found to depend on the germanium photoelectron line used for quantitative analysis; the $\mathrm{Ge} 3 \mathrm{~d}$ line yields the composition $\mathrm{Ge}_{1.0} \mathrm{C}_{1.9} \mathrm{O}_{2,1}$, while $\mathrm{Ge} 2 \mathrm{p}_{3 / 2}$ leads to stoichiometry $\mathrm{Ge}_{1.0} \mathrm{C}_{1.9} \mathrm{O}_{2.5}$. This result points to the inhomogeneity of the deposited layer in a direction perpendicular to the surface. The study of the dependence of the composition on the photoelectron take-off angle leads to the same conclusion. For $\theta=15^{\circ}$, the composition is $\mathrm{Ge}_{1.0} \mathrm{C}_{2.6} \mathrm{O}_{2.7}$; for $\theta=55^{\circ}$, corresponding to $c a .3 .2$ times higher sampling depth, $\mathrm{Ge}_{1.0} \mathrm{C}_{1.6} \mathrm{O}_{1.0}$ stoichiometry is obtained. The inhomogeneity, resulting in surface enrichment by carbon and oxygen, may be a consequence of the inter- action of the deposit surface with the ambient atmosphere during the transfer of the sample from the reactor to the spectrometer.

Binding energies of the $\mathrm{Ge} 3 \mathrm{~d}, 2 \mathrm{p}_{3 / 2} \mathrm{O} 1 \mathrm{~s}$, and kinetic energies Ge Auger LMM electrons are given for clean $\mathrm{Ge}$, $\mathrm{GeO}_{2}$, and deposits prepared by IRMPD and PSD (Table 1). It follows from the comparison of the data in Table 1 that the deposits are not a simple mixture of germanium oxide and hydrocarbon, but that germanium is probably bonded to both carbon and oxygen.

Optical absorption of the films obtained by IRMPD shows that they are transparent at wavelengths larger than $750 \mathrm{~nm}$, showing an absorption edge near $600 \mathrm{~nm}$ (Fig. 4). The films obtained by PSD, however, show an absorption edge near $1000 \mathrm{~nm}$. In larger wavelengths the deposits are more absorbent than those obtained by IRMPD. These differences arise from the two different compositions of the deposits.

TEM analysis of both kinds of film shows a non-uniform deposition formed by almost spherical particles (Fig. 5). The average diameter of the particles is $0.2 \mu \mathrm{m}$. The electron diffraction (SAD) shows a ring pattern characteristic of polycrystalline or very fine grain polycrystalline materials. Neither of the films is soluble in water, but both are soluble in hydrochloric acid.

The deposits produced by IRMPD possess extremely good

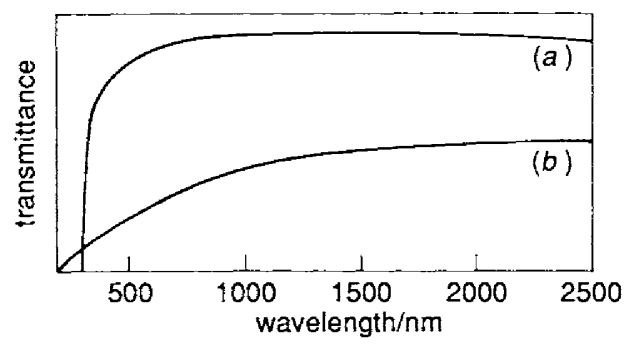

Fig. 4 Transmittance vs. wavelength of the films obtained (a) by IRMPD and $(b)$ PSD

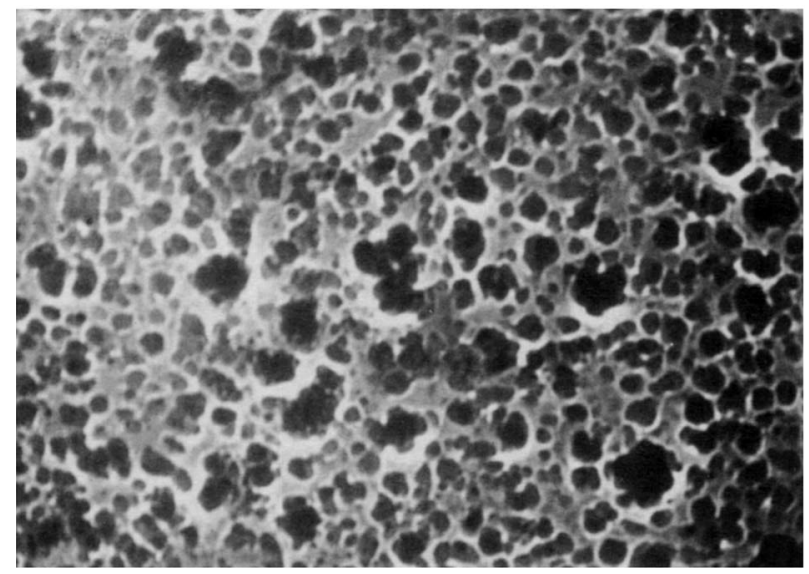

Fig. 5 Transmission electron micrograph $(\times 50000)$ of the film obtained by IRMPD

Table 1 ESCA binding energies, kinetic energies of Auger LMM electrons and Auger parameters for deposits, ${ }^{a}$ germanium and germanium oxide

\begin{tabular}{lccrrr}
\hline sample & $\mathrm{Ge} 3 \mathrm{~d} / \mathrm{eV}$ & $\mathrm{Ge} 2 \mathrm{p} / \mathrm{eV}$ & $\mathrm{Ge} \mathrm{A} / \mathrm{eV}$ & $\mathrm{O} \mathrm{Is/eV}$ & $\alpha_{1}{ }^{c} / \mathrm{eV}$ \\
\hline $\mathrm{Ge}$ & 29.6 & 1217.2 & 1145.1 & - & 1174.7 \\
$\mathrm{GeO}_{2}$ & 33.3 & 1220.4 & 1137.6 & 532.1 & 1170.9 \\
$\mathrm{~A}$ & 32.7 & 1219.8 & 1138.9 & 531.7 & 2362.3 \\
$\mathrm{~B}$ & 32.0 & 1221.1 & 1138.1 & 531.8 & 2358.5
\end{tabular}

${ }^{a}$ Sample A prepared by IRMPD; sample B prepared by PSD. ${ }^{b}$ Value of Auger parameter based upon Ge 3d peak. ${ }^{c}$ Based on Ge $2 \mathrm{p}_{3 / 2}$. 
adhesion to glass and sodium chloride, while those obtained by PSD can be easily removed mechanically from the substrate surface. This difference in adhesion seems to be related to the degradation of the initially adsorbed TMG.

The most interesting property of the deposited films is their reactivity towards ambient air. An expansion of air in the cell, from which volatile products were evacuated, leads to an immediate formation of methanol (new absorption bands at 1020,2960 , and $3560 \mathrm{~cm}^{-1}$ ). Moreover, the pattern of the IR spectrum of the deposit after subsequent re-evacuation is significantly changed (Fig. 3). The broad absorption band at $c a .850 \mathrm{~cm}^{-1}$ was shifted to lower wavenumbers; that at $c a$ $650 \mathrm{~cm}^{-1}$ was lost, while a new very broad $\left(v_{\mathrm{OH}}\right)$ absorption band developed between 3100 and $3600 \mathrm{~cm}^{-1}$.

We assume that the polymeric layers contain $\mathrm{CH}_{3}-\mathrm{O}-\mathrm{Ge}$ groups which react with air moisture:

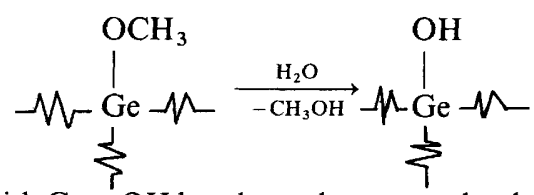

Polymers with $\mathrm{Ge}-\mathrm{OH}$ bonds can be expected to be unstable, owing to their possible dehydration to corresponding oxides. It is known ${ }^{10}$ that the similar reaction of germanols is very fast. Whether this dehydration is operative in the polymer layers is difficult to assess, since a broad $v_{\mathrm{OH}}$ band can be assigned either to water adsorbed onto $\mathrm{NaCl}^{30}$ or hydrogen $-\mathrm{Ge}-\mathrm{O} \cdots \mathrm{H} \cdots \mathrm{O}-\mathrm{Ge}-$ bridges within the polymer framework.

These results contribute to research into new syntheses and properties of reactive polymers that can be used ${ }^{31}$ in a variety of technological applications.

The authors thank Dr R. Pareja for his assistance with TEM measurements. L.D. acknowledges receipt of a visiting fellowship granted by CSIC (Spain) and CSAV (Czechoslovakia).

\section{References}

1 E. G. Rochow, in Comprehensive Inorganic Chemistry, Pergamon Press, Oxford, 1973, vol. 1.

2 M. P. Brown and E. G. Rochow, J. Am. Chem. Soc., 1960, 82, 4166.

3 W. Metlesies and H. Zeiss, J. Am. Chem. Soc., 1960, 82, 3324.

4 F. Rijkens, Organogermanium Compounds, Germanium Research Committee, Utrecht, 1960.
5 R. Schwarz and K. G. Knauff, Z. Anorg. Allg. Chem., 1954, 275 , 193.

6 L. Ross and M. Dräger, Z. Naturforsch., Teil B, 1984, 39, 868.

7 K. Haberle and M. Dräger, Z. Naturforsch., Teil B, 1984, 39 1541.

8 H. Puff, K. Braun, S. Franken, T. R. Kök and W. Schuh, J. Organometal. Chem., 1988, 349, 293.

9 H. Puff, K. Braun, S. Franken, T. R. Kök and W. Schuh, J. Organometal. Chem., 1987, 335, 167.

10 M. Lesbré, P. Mazerolles and J. Satgé, The Organic Compounds of Germanium, Wiley, London, 1971.

11 V. G. Minkina, Izv. Akad. Nauk SSSR, Neorg. Mater., 1988, 24, 803; Chem. Abstr., 109, 46855e.

12 M. Ya. Ivanov, T. N. Kupryashkina, S. G. Aloyan, N. A. Ovsyannikov, E. A. Ryabenko and A. A. Efremov, Sint. Soed. Plasma Soderzh. Uglevodorody, 1985, 141; Chem. Abstr., 97, $118354 z$.

13 J. Pola, R. Alexandrescu, J. Morjan and D. Sorescu, J. Anal. Appl. Pyrol., 1990, 18, 71.

14 J. Pola, Z. Bastl and J. Tláskal, Infrared Phys., 1990, 30, 335.

15 Z. Papoušková, J. Pola, Z. Bastl and J. Tláskal, J. Macromol. Sci.-Chem., 1990, 27, 1015.

16 J. Pola, in Frontiers of Organosilicon Chemistry, ed. A. R. Bassindale and P. P. Gaspar, The Royal Society of Chemistry, Cambridge, 1991, p. 159.

17 J. Pola and S. Simeonov, J. Chem. Soc., Perkin Trans. 2, 1991, 101 .

18 J. D. Briggs and M. P. Seah, Practical Surface Analysis by Auger and $X$-Ray Photoelectron Spectroscopy, Wiley, Chichester, 1983.

19 I. J. H. Scofield, J. Electron Spectrosc. Relat. Phenom., 1976, 8, 129.

20 R. West, H. R. Hunt and R. O. Whipple, J. Am. Chem. Soc., 1954, 76, 310.

21 O. H. Johnson and H. E. Fritz, J. Am. Chem. Soc., 1953, 75, 718.

22 Yu. Kh. Shaulov, A. K. Fedorov, G. Ya. Zueva, G. V. Borisyuk and V. G. Genchel, Zh. Fiz. Khim., 1970, 44, 2081.

23 S. W. Benson, Thermochemical Kinetics, Wiley, New York, 1976.

24 Beilstein's Handbuch der Organischen Chemie, Springer-Verlag, Berlin, 1959 and 1974, vol. 1, part 3, p. 162; part 5, p. 3026.

25 W. M. Shaub and S. H. Bauer, Int. J. Chem. Kinet., 1975, 7, 509

26 D. K. Russell, Chem. Soc. Rev., 1990, 19, 407.

27 D. F. McMillen, K. E. Lewis, G. P. Smith and D. M. Golden, J. Phys. Chem., 1982, 86, 709.

28 Yu. N. Samsonov, A. K. Petrov and A. V. Baklanov, React. Kinet. Catal. Lett., 1976, 5, 435.

29 F. Glockling, The Chemistry of Germanium, Academic Press, London, 1969.

30 V. C. Farmer and J. D. Russel, Spectrochim. Acta., 1962, 18, 461.

31 S. C. Tenhaeff and D. R. Tyler, Organometallics, 1991, 10, 473, and references therein.

Paper 2/01053D; Received 28th February, 1992 